\title{
Acquisition of cross-azole tolerance and aneuploidy in Candida albicans strains evolved to posaconazole
}

Rebekah J. Kukurudz ${ }^{1}$, Madison Chapel ${ }^{1 *}$, Quinn Wonitowy ${ }^{1 *}$, Abdul-Rahman Adamu Bukari ${ }^{1}$, Brooke Sidney $^{1}$, Riley Sierhuis ${ }^{1}$, Aleeza C. Gerstein ${ }^{1,2}$

*Equal contribution

\section{Affiliations:}

1. Department of Microbiology, The University of Manitoba

2. Department of Statistics, The University of Manitoba

\section{Corresponding Author:}

Aleeza Gerstein

Department of Microbiology, 45 Chancellor Circle, 213 Buller Building, Winnipeg, Manitoba, Canada, R3T 2N2

Running Title: Posaconazole evolution in Candida albicans

Keywords: drug resistance, drug tolerance, aneuploidy, experimental evolution 


\section{ABSTRACT}

2 A number of in vitro studies have examined the acquisition of drug resistance to the triazole

3 fluconazole, a first-line treatment for many Candida infections. Much less is known about

4 posaconazole, a newer triazole. We conducted the first in vitro experimental evolution of

5 replicates from eight diverse strains of $C$. albicans in a high level of the fungistatic drug

6 posaconazole. Approximately half of the 132 evolved replicates survived 50 generations of

7 evolution, biased towards some of the strain backgrounds. We found that although increases in

8 drug resistance were rare, increases in drug tolerance (the slow growth of a subpopulation of

9 cells in a level of drug above the resistance level) were common across strains. We also found

10 that adaptation to posaconazole resulted in widespread cross-tolerance to other azole drugs.

11 Widespread aneuploidy variation was also observed in evolved replicates from some strain

12 backgrounds. Trisomy of chromosomes 3, 6, and R was identified in 11 of 12 whole-genome

13 sequenced evolved SC5314 replicates. These findings document rampant evolved cross-tolerance

14 among triazoles and highlight that increases in drug tolerance can evolve independently of drug

15 resistance in a diversity of $C$. albicans strain backgrounds. 


\section{INTRODUCTION}

17 Drug resistance is a critical threat to global public health. Antimicrobial resistance is inherently an evolutionary phenomenon: drug-resistant individuals arise and spread within susceptible populations. The genetic basis and rate of adaptation in a drug is in part a deterministic process, akin to the evolutionary process under any environmental stress, influenced by the specifics of the environment, the microbial population size, the mutation rate, and the effect size of available beneficial mutations. Unlike bacteria, which frequently acquire plasmid-mediated beneficial genes and alleles from the environment, fungal microbes primarily adapt via vertical transmission. Genomic variation within evolving populations often includes small-scale point mutations and insertions and deletions as well as larger-scale karyotypic mutations in ploidy (the number of chromosome sets), aneuploidy (copy number change in one or several chromosomes), and zygosity (the number of alleles at a given position in the genome) (Selmecki et al. 2015; Ene et al. 2018, 2021; Wang et al. 2018). Few antifungal drug classes are currently approved for the treatment of fungal infections. One strategy to prolong the utility of existing drugs is to understand better the factors that influence fungal resistance acquisition, to reduce the likelihood that resistance will arise.

In addition to drug resistance, which is often measured as the minimum inhibitory concentration of drug that reduces growth by some amount (MIC, e.g., $50 \%$ or $80 \%$ ) after $24 \mathrm{~h}$, drug tolerance has recently emerged as an important parameter in characterizing drug response in fungal species. Fungal tolerance (which is distinct from bacterial tolerance (Levin-Reisman et al. 2017)) is defined as the proportion of the population that grows slowly in drug concentrations above the minimum inhibitory concentration (Rosenberg et al. 2018; Berman and Krysan 2020). Although few studies have quantified tolerance yet, it may play a role in persistent candidemia (Rosenberg et al. 2018) and mortality (Levinson et al. 2020). From an evolutionary perspective, beneficial mutations that arise in populations evolving in fungistatic environments that primarily inhibit rather than kill susceptible cells could act in two distinct pathways: they can increase resistance (i.e., increase the MIC), or they can increase tolerance (i.e., enable a larger proportion of the population to grow above the MIC). A recent screen of 235 clinical Candida spp. isolates

4 found that resistant isolates also tended to be more tolerant to the fungistatic drug fluconazole 
47 Berman 2020). As many antifungal drugs are fungistatic rather than fungicidal, increasing drug

48 tolerance may be an unappreciated yet critical selective avenue for fungal populations adapting

49 to a drug.

Relatively few species account for most human fungal infections, with Candida albicans the primary species responsible for mucosal disease, Aspergillus fumigatus for allergic disease, and Trichophyton spp. for skin infections (Bongomin et al. 2017). The azole drugs fluconazole and voriconazole are first-line treatments for candidiasis and aspergillosis, respectively (Pappas et al. 2016; Patterson et al. 2016). Primarily through the study of fluconazole-resistant $C$. albicans strains, the genetic basis of two major adaptive pathways have been identified: the first involves alterations or overexpression of ERG11, which produces the target demethylase (Asai et al. 1999; Lamb et al. 2000; Selmecki et al. 2008; Flowers et al. 2015; Paul et al. 2019; Lee et al. 2020); the second is through the up-regulation of drug efflux pumps encoded by $C D R 1, C D R 2$, TAC1, MRR1, and MDRl (Sanglard et al. 1995; Asai et al. 1999; Lamb et al. 2000; Coste et al. 2006; Selmecki et al. 2008; Flowers et al. 2015; Paul et al. 2019; Lee et al. 2020). One of the newest azoles, posaconazole, effectively treated infections resistant to first-line azoles in $A$. fumigatus, C. albicans, and C. neoformans (Xiao et al. 2004; Chau et al. 2004; Firinu et al. 2011; Sionov et al. 2012). Intriguingly, although specific point mutations in ERG11 homologues confer posaconazole cross-resistance to azoles and other antifungal drugs in Aspergillus spp. (Lockhart et al. 2011; D'Agostino et al. 2018; Abastabar et al. 2019), single C. albicans ERG11 point mutations do not provide the same degree of posaconazole cross-resistance (MacCallum et al. 2010; Sanglard and Coste 2016; Warrilow et al. 2019). Rather, it seems that multiple ERG11 mutations are required for posaconazole resistance (Li et al. 2004). This may be attributable to the extended side chain of posaconazole interacting with an additional domain of the target enzyme (Li et al. 2004; Xiao et al. 2004; Chau et al. 2004; Katragkou et al. 2012). populations is primarily achieved through mitosis, though parasexual reproduction is also possible (Hickman et al. 2013; Ene and Bennett 2014). In addition to point mutations, unicellular fungal microbes seem prone to acquiring chromosomal aneuploidies during adaptation (Gerstein and Berman 2015; Gerstein and Sharp 2021), and mitotic recombination results in lossofheterozygosity. Intriguingly, exposure to the triazole drugs fluconazole, ketoconazole, voriconazole, and itraconazole potentiate the appearance of chromosomal aneuploidy (Harrison 
78 et al. 2014). Extra copies of chromosomes 3 (Perepnikhatka et al. 1999; Ford et al. 2015), 4

79 (Perepnikhatka et al. 1999; Anderson et al. 2017), and 5 (Coste et al. 2006; Selmecki et al. 2006,

80 2008; Ford et al. 2015; Todd et al. 2019) have previously been shown to confer increased

81 resistance to fluconazole, hence azole drugs cause both cause a generalized increased rate of

82 aneuploidy as well as selection for specific aneuploidies. Resistance has been attributed to

83 increased gene dosage of drug transporters or their transcriptional activators $(C D R 1, C D R 2$,

84 CZR1, and MRR1 on chr3 (Sanglard et al. 1995, 1997; Chau et al. 2004; Coste et al. 2004, 2006;

85 Todd and Selmecki 2020), TAC1 on chr5 (Selmecki et al. 2008)), stress response proteins (PBS2

86 on chr3 (Todd and Selmecki 2020); CGR1 on chr4 (Todd and Selmecki 2020)), and the target

87 enzyme (ERG11 on chr5 (Chau et al. 2004; Selmecki et al. 2008)). Furthermore, since many

88 genes are affected by an aneuploidy, non-targeted effects may be more common than with single-

89 gene mutations; for example, chr2 aneuploidy selected under caspofungin exposure confers

90 enhanced survival by different mechanisms to hydroxyurea (Yang et al. 2019) and tunicamycin

91 (Yang et al. 2021b). In some cases, this may provide an enhanced selective effect for aneuploidy

92 to sweep through a population. In other scenarios, gene overexpression could be selectively

93 disadvantageous (Yang et al. 2021a), reducing the potential fitness benefit. Whether consistent

94 posaconazole exposure also selects for beneficial aneuploidy has not been determined.

95 Here, we conducted the first in vitro experimental evolution of eight diverse strains of $C$.

96 albicans in the fungistatic drug posaconazole. We found that increases in drug tolerance to

97 posaconazole were common across strain backgrounds, while increases in drug resistance were

98 rare. We also found that adaptation to posaconazole resulted in widespread cross-tolerance to

99 other azoles and widespread increases in genome size. 


\section{MATERIALS AND METHODS}

\section{Strains and evolution}

Eight clinical strains of $C$. albicans that span ancestral fitness to fluconazole (Gerstein and Berman, 2020) were selected (FH1, (Fonzi and Irwin 1993); SC5314, (Lockhart et al. 2002); T101 (Odds et al. 2007); GC75, P75016, P76055, P78048, and P87, (Wu et al. 2007)). Freezer stock was streaked onto YPD agar plates, a standard lab yeast rich medium $(2 \% \mathrm{w} / \mathrm{v}$ peptone, $2 \%$ w/v yeast extract, $1.8 \% \mathrm{w} / \mathrm{v}$ agar, $1 \% \mathrm{w} / \mathrm{v}$ glucose, $0.00016 \% \mathrm{w} / \mathrm{v}$ adenine sulfate, $0.00008 \% \mathrm{w} / \mathrm{v}$ uridine, $0.1 \% \mathrm{v} / \mathrm{v}$ of each chloramphenicol and ampicillin), and incubated at room temperature for $72 \mathrm{~h}$. Twelve single colonies from each of the eight strains were chosen haphazardly and

110 transferred into $1 \mathrm{~mL}$ of liquid YPD in a $3 \mathrm{~mL}$ 96-well box, sealed with Breathe-Easier sealing membranes (Electron Microscopy Sciences, PA, United States), and incubated for $24 \mathrm{~h}$ at $30{ }^{\circ} \mathrm{C}$,

112 creating twelve replicate lines from each strain. From each replicate, $100 \mu \mathrm{L}$ was frozen down in

$11330 \%$ glycerol and stored at $-70{ }^{\circ} \mathrm{C}$ as the ancestral culture.

114 We initiated two sets of evolution experiments similarly. To initiate both sets, the optical

115 density was measured from ancestral replicates grown in YPD, and wells were standardized to an

$116 \mathrm{OD}_{600}$ of 0.01 . A 1:10 dilution was then done in parallel into either YPD $+0.5 \mu \mathrm{g} / \mathrm{mL}$

117 posaconazole (hereafter referred to as POS) or YPD alone (YPD). For the first set, replicate lines

118 were initially incubated statically at $30^{\circ} \mathrm{C}$ for $24 \mathrm{~h}$, followed by $1: 1000$ serial dilutions into fresh

119 medium (POS or YPD) every $24 \mathrm{~h}$ for four days, for a total of $\sim 50$ generations of evolution. The

120 second set of experiments followed a very similar method, except all replicates were initially

121 incubated statically at $30^{\circ} \mathrm{C}$ for $72 \mathrm{~h}$, and then four $1: 1000$ serial dilutions were done into fresh

122 POS medium every $72 \mathrm{~h}$. Twelve replicates from strains P87, GC75, and SC5314 were evolved

123 with both $24 \mathrm{~h}$ and $72 \mathrm{~h}$ transfers in a POS pilot study that followed the same protocol before the 124 main studies.

125 In all cases, evolved replicates were frozen down in triplicate in $15 \%$ glycerol after the

126 fifth transfer and stored at $-70{ }^{\circ} \mathrm{C}$. In total, 132 replicates were evolved for each transfer duration

127 in POS $((12$ replicates x 3 strains $)+(12$ replicates x 8 strains $)=132$ replicates $)$ while 96

128 replicates were evolved for each in YPD. Replicates were considered extinct at the end of the 129 experiment if they were unable to be revived from the evolved freezer stock. 
Fitness in the evolutionary environment

Fitness in the evolutionary environment was measured as OD600 after $24 \mathrm{~h}$ and $72 \mathrm{~h}$ incubation. Ancestral and evolved replicates were grown from frozen by transferring $5 \mu \mathrm{L}$ of

133 thawed freezer stock into $500 \mathrm{~mL}$ liquid YPD and incubated for $48 \mathrm{~h}$ at $30{ }^{\circ} \mathrm{C}$. Each replicate 134 was standardized to OD 6000.01 in liquid YPD. Next, $100 \mu \mathrm{L}$ of standardized culture was placed 135 into each well of a 96-well round bottom plate, and $100 \mu \mathrm{L}$ of YPD plus posaconazole was added 136 to each well for a final concentration of $0.5 \mu \mathrm{g} / \mathrm{mL}$ posaconazole. All plates were covered with a

137 Breathe-Easier sealing membrane and incubated statically at $30{ }^{\circ} \mathrm{C}$ for $72 \mathrm{~h}$, with $\mathrm{OD}_{600}$

138 measurements taken every $24 \mathrm{~h}$.

\section{Drug Susceptibility}

141 Drug susceptibility was measured by disk diffusion assays in posaconazole and fluconazole in all

142 replicates. In addition, SC5314 replicates were also assayed in miconazole, clotrimazole,

143 voriconazole, 5-fluorocytosine, and nystatin. Posaconazole disks were prepared by adding $4 \mu \mathrm{L}$ 144 of $0.625 \mathrm{mg} / \mathrm{mL}$ posaconazole stock in DMSO to blank susceptibility disks (Fisher Scientific,

145 Ottawa, ON, Canada) for a final concentration of $2.5 \mathrm{mg}$. All other susceptibility disks were 146 purchased: fluconazole $(25 \mu \mathrm{g})$ (Fisher Scientific, Ottawa, ON, Canada); miconazole (50 $\mu \mathrm{g})$, 147 clotrimazole $(50 \mu \mathrm{g})$, voriconazole $(1 \mu \mathrm{g}), 5$-fluorocytosine $(1 \mu \mathrm{g})$, and nystatin (100 IU)

148 (BioRad Laboratories, Hercules, California, USA).

149 Ancestral and evolved replicates were grown from frozen in liquid YPD at $30{ }^{\circ} \mathrm{C}$ for 48

150 h. Each replicate was standardized to $\mathrm{OD}_{600} 0.01$. Next, $100 \mu \mathrm{L}$ of standardized culture was 151 spread, in duplicate, onto $15 \mathrm{~mL}$ YPD agar plates, using sterile $5 \mathrm{~mm}$ glass beads. A single drug 152 susceptibility disk was applied to the center of each plate, and plates were incubated at $30{ }^{\circ} \mathrm{C}$. 153 After $48 \mathrm{~h}$, each plate was placed on a lightbox and photographed from above using a Canon 154 EOS Rebel SL2.

155 Photographs were cropped, converted to 8-bit, inverted, and brightness and contrast were 156 altered using ImageJ (Schneider et al., 2012) to obtain bright colonies against a black

157 background. Resistance $\left(\mathrm{RAD}_{20}\right)$ and tolerance $\left(\mathrm{FoG}_{20}\right)$ were quantified from the images using 158 the diskImageR $\mathrm{R}$ package, following recommendations specified in the diskImageR vignette V2 159 (Gerstein et al. 2016), https://www.microstatslab.ca/diskimager.html). The reported $\mathrm{RAD}_{20}$ and $160 \mathrm{FoG}_{20}$ values are averages across multiple biological and technical replicates. 


\section{Ploidy Variation}

162 Flow cytometry was used to determine if evolved replicates had altered ploidy (all were initially

163 diploid). Ancestral and surviving evolved replicates were fixed, stained, and measured in

164 parallel. $5 \mu \mathrm{L}$ of each replicate was inoculated from frozen into $500 \mu \mathrm{L}$ of liquid YPD in a deep

165 96-well box, covered with a Breathe-Easier sealing membrane, and shaken at $350 \mathrm{rpm}$ at $30{ }^{\circ} \mathrm{C}$

166 for $48 \mathrm{~h}$. After $48 \mathrm{~h}, 10 \mu \mathrm{L}$ was subcultured into $500 \mu \mathrm{L}$ of fresh media, and shaken at $350 \mathrm{rpm}$ at

$16730{ }^{\circ} \mathrm{C}$ for 4 h. $200 \mu \mathrm{L}$ of subculture was then transferred to a 96-well round bottom plate and

168 pelleted. Pellets were resuspended in $20 \mu \mathrm{L}$ of 50:50 Tris-EDTA (TE), fixed by slowly adding

$169180 \mu \mathrm{L}$ of $100 \%$ cold ethanol, and stored wrapped in aluminum foil at $-20{ }^{\circ} \mathrm{C}$ for at least $12 \mathrm{~h}$.

170 The fixed culture was pelleted, washed in $200 \mu \mathrm{L}$ of TE, pelleted again, and resuspended in 50

$171 \mu \mathrm{L}$ of $1 \mathrm{mg} / \mathrm{mL}$ RNAse A solution (New England Biolabs, Ipswich, Massachusetts, United

172 States) and statically incubated at $37^{\circ} \mathrm{C}$ for $3 \mathrm{~h}$. After the $3 \mathrm{~h}$ incubation, the replicates were

173 pelleted and resuspended in $50 \mu \mathrm{L}$ TE and $50 \mu \mathrm{L}$ of 1:100 SYTOX: TE solution and incubated at

174 room temperature in the dark overnight. The next day the replicates were pelleted then

175 resuspended in $700 \mu \mathrm{L}$ of TE. All centrifugation steps were done at $1000 \mathrm{x}$ g for 5 minutes.

176 Flow cytometry was performed on an SH800S Cell Sorter (Sony Biotechnology Inc, San

177 Jose, California, United States). All replicates had an event rate of 600-1000 events/second and a

178 total of 10000 events were recorded. Data was uploaded to FlowJo (Tree Star, Ashland, Oregon,

179 United States), and debris was excluded via gating. Each replicate population was then fit with

180 the Watson (pragmatic) cell cycle algorithm (Watson et al. 1987) to determine the mean G1

181 peak.

182

\section{DNA extraction}

184 Genomic DNA was extracted from two ancestral strain replicates, and 12 evolved replicates from

185 SC5314, the strain used for the $C$. albicans reference genome. $30 \mu \mathrm{L}$ of each replicate were

186 transferred into $3 \mathrm{~mL}$ of YPD and incubated shaking overnight at $37^{\circ} \mathrm{C}$. The culture was

187 centrifuged at $2500 \mathrm{rpm}$ for 3 minutes, and the supernatant was discarded. The pellet was

188 resuspended in $500 \mu \mathrm{L}$ of TENTS buffer (100 mM NaCl, $10 \mathrm{mM}$ Tris pH 8.0, $1 \mathrm{mM}$ EDTA, 2\%

189 Triton X 100, and 1\% SDS), $100 \mu \mathrm{L}$ of glass beads, and $200 \mu \mathrm{L}$ phenol:chloroform: IAA and

190 vortexed for 20 minutes at $4{ }^{\circ} \mathrm{C}$ followed by centrifugation for 10 minutes at $13500 \mathrm{rpm}$. After 
191 centrifugation, $350 \mu \mathrm{L}$ of supernatant was transferred to a sterile microcentrifuge tube, and $1 \mathrm{~mL}$

192 of cold $100 \%$ ethanol was added and left overnight at $-20^{\circ} \mathrm{C}$ to allow for DNA precipitation.

193 This was followed by centrifugation at $13500 \mathrm{rpm}$ for 10 minutes, and the pellet was

194 resuspended in $50 \mu \mathrm{L}$ of molecular biology grade water. One microliter of $10 \mathrm{mg} / \mathrm{mL}$ RNAse A

195 was added and incubated at $37^{\circ} \mathrm{C}$ for $1 \mathrm{~h}$, after which $2 \mu \mathrm{L}$ of $20 \mathrm{mg} / \mathrm{mL}$ proteinase $\mathrm{K}$ (Fisher

196 Scientific, Ottawa, Ontario, Canada) was added and incubated at $37^{\circ} \mathrm{C}$ for $1.5 \mathrm{~h}$. After

197 incubation, $200 \mu \mathrm{L}$ of molecular biology grade water and $300 \mu \mathrm{L}$ of phenol:chloroform: IAA was

198 added, and samples were centrifuged at $13500 \mathrm{rpm}$ for 10 minutes. Next, the supernatant was

199 transferred to a sterile microcentrifuge tube, $4 \mu \mathrm{L}$ of $5 \mathrm{M} \mathrm{NaCl}$ and $400 \mu \mathrm{L}$ of cold $100 \%$ ethanol

200 were added and DNA was precipitated for at least 10 minutes at $-20{ }^{\circ} \mathrm{C}$. Tubes were then

201 centrifuged at $13500 \mathrm{rpm}$ for 10 minutes, the supernatant was discarded, and the pellet was left

202 overnight. The DNA pellet was then resuspended in $40 \mu \mathrm{L}$ of molecular biology grade water.

203 DNA quality was assessed using the Thermo Scientific ${ }^{\mathrm{TM}}$ NanoDrop 2000, and DNA

204 concentration was measured using a Qubit ${ }^{\circledR}$ 2.0 Fluorometer (following the Invitrogen ${ }^{\mathrm{TM}}$

205 Qubit ${ }^{\mathrm{TM}}$ dsDNA BR Assay Kit) (Thermo Fisher Scientific, Waltham, Massachusetts, United

206 States). Whole-genome sequencing was performed by the Microbial Genome Sequencing Center

207 (Pittsburgh, USA) using the Illumina NextSeq 550 platform to a calculated depth of $\sim 40 \times$

208 pairedend reads of $2 \times 150 \mathrm{bp}$.

210 Karyotype analysis

211 To analyze the whole-genome sequences for karyotypic variation in evolved SC5314 replicates,

212 we used YMAP, a computational pipeline that visualizes copy number variation and loss of

213 heterozygosity (Abbey et al. 2014). Mitochondrial DNA was excluded from the coverage

214 analysis. Paired-end read data were uploaded and analyzed using the SC5314 A21-s02-m09-r07

215 reference genome. Both baseline and experimental ploidy were left at the default values (two,

216 i.e., diploid), and correction was enabled for GC-content bias and chromosome-end bias.

217 Smaller-scale CNVs were also evaluated by comparing the copy number at each position in

218 evolved strains to the copy number in two sequenced ancestral strains. Positions elevated only in

219 evolved strains were further examined individually, and the location mapped to the genome using

220 the Candida Genome Database (candidagenome.org). 


\section{RESULTS}

\section{Survival and fitness in posaconazole evolution}

223 Replicate lines from eight clinical strains of $C$. albicans were passaged with 1:1000 dilutions

224 every $24 \mathrm{~h}$ or $72 \mathrm{~h}$, for a total of five transfers in YPD + $0.5 \mathrm{ug} / \mathrm{mL}$ posaconazole (POS) and in

225 YPD. The level of posaconazole was above the $\mathrm{MIC}_{50}$ of all ancestral strains, representing a

226 strong selective pressure. We use the term "ancestral replicates" to indicate populations initiated

227 from single colony replicates before evolution, and the term "evolved replicates" to refer to the

228 replicates that survived the evolution experiment. No replicates survived in the POS $24 \mathrm{~h}$ transfer

229 experiment, while approximately half of the replicates (67) survived to the end of the POS $72 \mathrm{~h}$

230 transfer experiment. Replicate survival to $72 \mathrm{~h}$ transfers in POS was not equal among strain

231 backgrounds (Figure 1). Surprisingly, ancestral fitness in the evolutionary drug environment was

232 not significantly correlated with the number of surviving replicates after evolution (Figure 1;

233 ancestral fitness measured as optical density after $72 \mathrm{~h}$ of growth in POS, Pearson's correlation, $\mathrm{t}_{6}$

$234=0.91, P=0.40$ ). This lack of correlation indicates that strain-specific genomic differences that

235 influence something other than ancestral fitness likely correlate with evolvability to POS. All

236 replicate lines survived $24 \mathrm{~h}$ and $72 \mathrm{~h}$ transfers in the standard rich medium YPD. The majority

237 of the remaining analysis is based on the $72 \mathrm{~h}$ transfer experiment in POS, except where

238 indicated. 


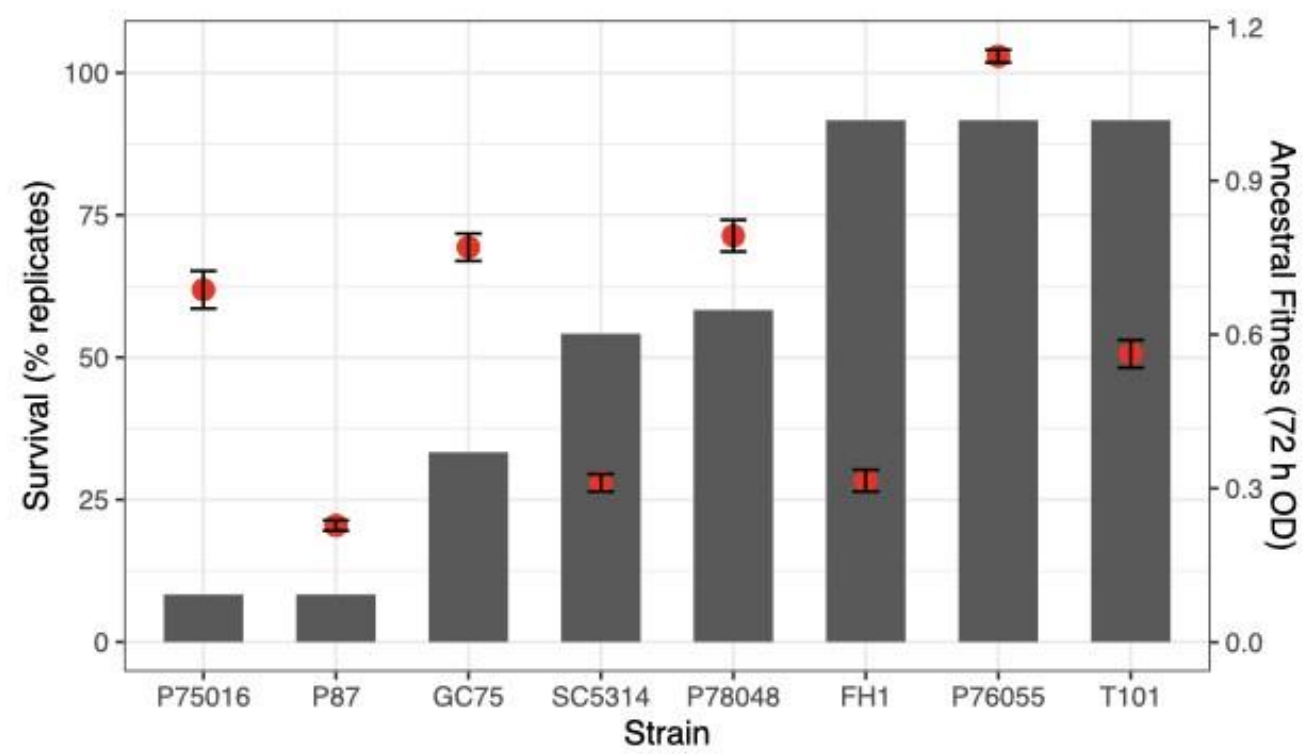

Figure 1. Differential survival of evolved replicates to five passages posaconazole. The grey bars indicate the percentage of replicates that survived to the end. Red dots indicate ancestral fitness (optical density after $72 \mathrm{~h}$ of growth in the evolutionary environment), shown on the right vertical axis. Each dot is the mean $+/-$ SE of two biological replicates. The percent of replicates that survived was associated with ancestral strain fitness.

Evolved replicates from the five strains with the highest number of surviving replicates

242 (P78048, SC5314, FH1, P76055, T101) grew to a higher optical density than ancestral replicates

243 after $24 \mathrm{~h}$ in POS (Figure 2; t-test results in Table 1) and four of the five strains retained the

244 advantage after $72 \mathrm{~h}$ of growth (Figure 2, Table 1). There were not enough surviving replicates

245 from P87 or P75016 to properly conduct statistical tests, though the one surviving replicate from

246 P75016 also very clearly has a fitness advantage over the ancestral replicates. Evolved replicates

247 from GC75 had no improvement over ancestral replicates at $24 \mathrm{~h}$ or $72 \mathrm{~h}$. Across all strain

248 backgrounds, there was an inconsistent tradeoff between improvement in fitness in drug and

249 reduction of fitness in YPD (Figure S1; t-test results in Table 2). Evolved replicates from three

250 strains (P78048, SC5314, FH1) had a minor reduction in fitness in YPD at $24 \mathrm{~h}$, which continued

251 to $72 \mathrm{~h}$ for SC5314 and FH1. T101 had a minor improvement in fitness at $24 \mathrm{~h}$ in YPD. Of note,

252 the magnitude of fitness difference between statistically-significant ancestral and evolved

253 replicates tended to be considerably less in YPD compared to drug (Table 1). 
bioRxiv preprint doi: https://doi.org/10.1101/2022.01.06.475277; this version posted January 6, 2022. The copyright holder for this preprint (which was not certified by peer review) is the author/funder, who has granted bioRxiv a license to display the preprint in perpetuity. It is made available under aCC-BY-NC-ND 4.0 International license.
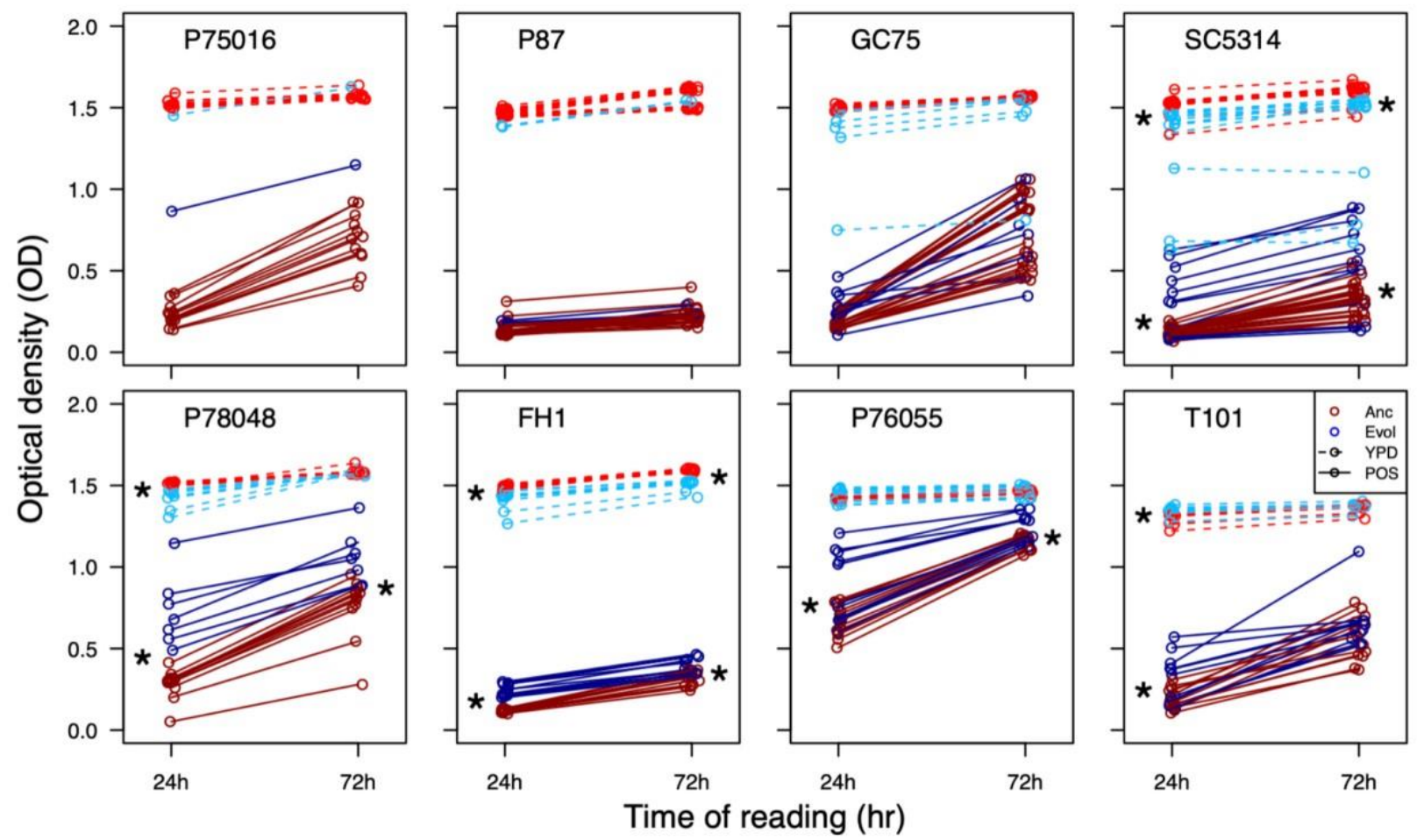

Time of reading $(\mathrm{hr})$

Figure 2. Fitness of ancestral and evolved replicates grown in YPD and POS. Optical density was measured at 24 $\mathrm{h}$ and $72 \mathrm{~h}$. Shown here is only the replicates that were evolved through $72 \mathrm{~h}$ transfers in POS. Evolved replicates grown in YPD are indicated with brighter colours and dashed lines, replicates grown in POS are darker colours and full lines. Stars indicate statistical significance in a t-test comparing ancestral and evolved replicates at that time point (24 or $72 \mathrm{~h}$ of growth). 
Table 1. T-test results comparing optical density of ancestral and evolved replicates grown for $24 \mathrm{~h}$ (left) and $72 \mathrm{~h}$ (right) in POS (top) and YPD (bottom).

\begin{tabular}{l|cl|cl|} 
& \multicolumn{2}{|c|}{ Posaconazole 24 h } & \multicolumn{2}{c|}{ Posaconazole 72 $\mathbf{~}$} \\
Strain & Evol-Anc statistic & Evol-Anc & statistic \\
\hline GC75 & 0.08 & $\mathrm{t}_{7.9}=-2.0, p=0.09$ & -0.08 & $\mathrm{t}_{10.8}=0.8, p=0.45$ \\
SC5314 & 0.17 & $\mathrm{t}_{12.2}=-2.9, p=0.013$ & 0.18 & $\mathrm{t}_{13.6}=-2.2, p=0.048$ \\
P78048 & 0.5 & $\mathrm{t}_{8.2}=-5.4, p<0.001$ & 0.33 & $\mathrm{t}_{15.0}=-3.9, p=0.002$ \\
FH1 & 0.13 & $\mathrm{t}_{11.5}=-11.4, p<0.001$ & 0.08 & $\mathrm{t}_{19.8}=-4.3, p<0.001$ \\
P76055 & 0.2 & $\mathrm{t}_{13.5}=-2.9, p=0.013$ & 0.09 & $\mathrm{t}_{15.0}=-3.0, p=0.009$ \\
T101 & 0.12 & $\mathrm{t}_{13.2}=-2.3, p=0.036$ & 0.09 & $\mathrm{t}_{20.1}=-1.5, p=0.15$ \\
\hline
\end{tabular}

\begin{tabular}{l|cl|ll|} 
& \multicolumn{2}{|c|}{$\begin{array}{c}\text { YPD 24 } \mathbf{h} \\
\text { Strain }\end{array}$} & Evol-Anc & statistic \\
\hline GC75 & -0.15 & $\mathrm{t}_{7}=-1.65, p=0.14$ & -0.12 & $\mathrm{t}_{7}=1.36, p=0.22$ \\
SC5314 & -0.24 & $\mathrm{t}_{12.3}=2.86, p=0.014$ & -0.24 & $\mathrm{t}_{12.3}=2.74, p=0.018$ \\
P78048 & -0.09 & $\mathrm{t}_{7.2}=-3.5 .6, p=0.009$ & -0.01 & $\mathrm{t}_{13.9}=0.84, p=0.42$ \\
FH1 & -0.08 & $\mathrm{t}_{10.6}=4.25, p=0.002$ & -0.09 & $\mathrm{t}_{11}=9.05, p<0.001$ \\
P76055 & 0.02 & $\mathrm{t}_{11.0}=-1.3 .6, p=0.22$ & -0.002 & $\mathrm{t}_{11.2}=0.14, p=0.89$ \\
T101 & 0.04 & $\mathrm{t}_{20.6}=-3.0 .6, p=0.007$ & 0.01 & $\mathrm{t}_{20.7}=-1.16, p=0.26$ \\
\hline
\end{tabular}

256 Widespread decreases in drug resistance and increases in drug tolerance in POS evolved replicates

257 Drug susceptibility was computationally quantified as the radius of inhibition on a disk diffusion

258 plate (Gerstein et al. 2016). Six strain backgrounds evolved an increase in susceptibility (Figure

259 3; GC75: t7.6 = -2.7, p = 0.029; SC5314: $\mathrm{t}_{12.7}=-2.25, \mathrm{p}=0.043 ; \mathrm{P} 78048: \mathrm{t} 6.8=-7.7, \mathrm{p}=0.0001$;

260 FH1: $\mathrm{t}_{13.0}=-4.3, \mathrm{p}=0.0008$; strains P75016 and P87 had too few replicates for statistical

261 testing). Six replicates from four strains did deviate from the rest and acquired increased

262 resistance (reduced susceptibility; P75016, GC75, SC5314, and P78048). Evolved replicates

263 from the two strain backgrounds with the highest number of surviving replicates did not change

264 in susceptibility (P76065: $\left.\mathrm{t}_{13.6}=-1.4, \mathrm{p}=0.17 ; \mathrm{T} 101: \mathrm{t}_{15.4}=0.8, \mathrm{p}=0.42\right)$. The opposite result

265 was seen for drug tolerance, which is computationally determined as $\mathrm{FoG}_{20}$, the fraction of

266 growth between the disk and $\operatorname{RAD}_{20}$ (Gerstein et al. 2016); Figure 3). Evolved replicates from six

267 strain backgrounds increased in tolerance, while two of the strains with a higher number of

268 surviving replicates did not change (Figure 3; GC75: $\mathrm{t}_{11.6}=-14.5, \mathrm{p}<0.0001 ; \mathrm{SC} 5314: \mathrm{t}_{14.0}=$

269 12.63, $\mathrm{p}<0.0001 ; \mathrm{P} 78048: \mathrm{t}_{6.1}=-7.3, \mathrm{p}=0.0003 ; \mathrm{FH} 1: \mathrm{t}_{19.8}=0.6, \mathrm{p}=0.59 ; \mathrm{P} 76055: \mathrm{t}_{18.0}=-2.2$, 
$\left.270 \mathrm{p}=0.042 ; \mathrm{T} 101: \mathrm{t}_{20.1}=0.9, \mathrm{p}=0.50\right)$. Evolved replicates from across strain backgrounds more

271 consistently increased in tolerance rather than resistance, suggesting that tolerance is either more

272 evolvable than resistance, or was the primary phenotype under selection in POS.

273 All evolved replicates were also assayed for the evolution of cross-resistance and/or

274 cross-tolerance to the most common triazole, fluconazole (FLC). Results in FLC were similar to

275 POS; evolved replicates tended to increase in FLC susceptibility (decrease in resistance) yet

276 increase in FLC tolerance. Interestingly, in a number of strain backgrounds, POS-evolved

277 replicates increased in FLC resistance to a higher degree than they had in POS. This lead on

278 occasion to the loss of a significant difference in susceptibility between ancestral and evolved

279 replicates in some strain backgrounds, though it is clear that the majority of evolved replicates in

280 most backgrounds increased in FLC susceptibility (Figure 3; FLC resistance - GC75: t7.1 $=-0.52$,

$281 \mathrm{p}=0.62 ; \mathrm{SC} 5314: \mathrm{t}_{13.7}=-2.51, \mathrm{p}=0.025 ; \mathrm{P} 78048: \mathrm{t}_{6.0}=-0.93, \mathrm{p}=0.39 ; \mathrm{FH} 1: \mathrm{t}_{11.2}=-1.9, \mathrm{p}=$

$2820.08 ;$ P76055: $\mathrm{t}_{16.8}=-2.6, \mathrm{p}=0.02$; tolerance-GC75: $\mathrm{t}_{13.2}=-13.2, \mathrm{p}<0.0001 ; \mathrm{SC5314:} \mathrm{t}_{13.5}=-$

283 8.26, $\mathrm{p}<0.0001 ; \mathrm{P} 78048: \mathrm{t}_{6.0}=-12.7, \mathrm{p}<0.0001 ; \mathrm{FH} 1: \mathrm{t}_{11.2}=-1.9, \mathrm{p}=0.09 ; \mathrm{P} 76055: \mathrm{t}_{18.8}=1.3$,

$284 \mathrm{p}=0.21$ ). The ancestral and evolved replicates of T101 are resistant to FLC and changes to FLC

285 tolerance in evolved replicates can not be examined in this framework.
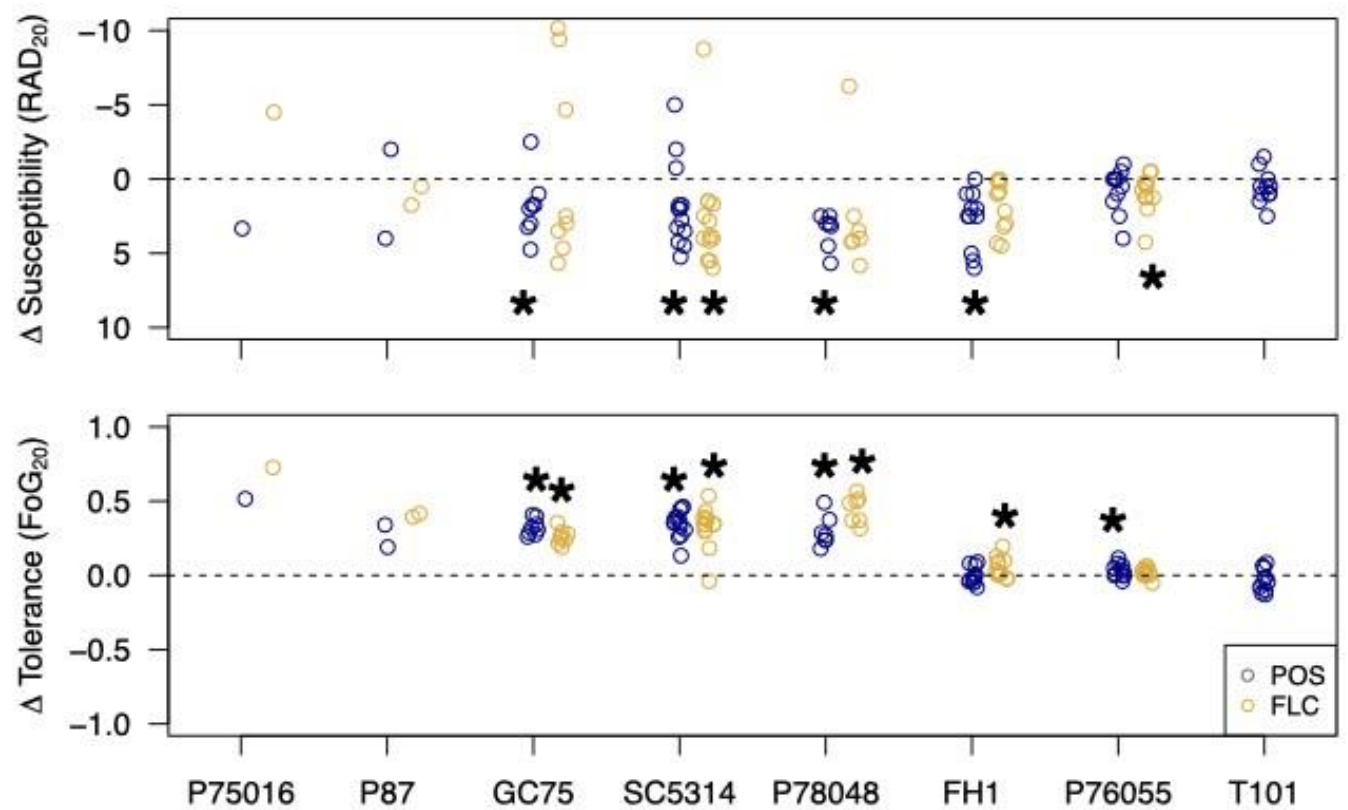

Figure 3. Susceptibility (top) and tolerance (bottom) of posaconazole-evolved replicates assayed on posaconzole and fluconazole disks. Shown is the difference in phenotype between the evolved replicate and the median of 12 ancestral replicates. A negative change in susceptibility in the evolved replicate indicates an increase in resistance, and the $y$-axis of the top panel is reversed to reflect this. Stars indicate a significance difference compared to the ancestral replicates from a t-test $(\mathrm{p}<0.05)$. 


\section{Inconsistent changes in drug resistance and drug tolerance in YPD evolved replicates}

288 Replicates that were evolved with $24 \mathrm{~h}$ and $72 \mathrm{~h}$ transfers in YPD exhibited much smaller

289 changes in resistance and tolerance, though some evolved strains did differ significantly

290 compared to the ancestors (Figure S1, Table S1). There was no apparent pattern between strain

291 background and the specific evolved changes. Evolved replicates from strain P87 (a strain with

292 few surviving POS replicates) in both the $24 \mathrm{~h}$ and $72 \mathrm{~h}$ transfer experiments had significantly

293 increased susceptibility. By contrast, evolved replicates from strain P76055 and T101, the two

294 strains with the most surviving POS replicates, had significantly decreased susceptibility (in both

295 experiments for strain P76055 while only in the $24 \mathrm{~h}$ transfers for strain T101). Evolved

296 replicates from strain GC75 in the $24 \mathrm{~h}$ transfer experiment decreased in tolerance, while

297 replicates from strain $\mathrm{FH} 1$ in the $24 \mathrm{~h}$ transfer experiment increased in tolerance.

299 Widespread karyotypic changes after posaconazole evolution

300 Genome size changes in POS evolved replicates were examined with flow cytometry.

301 Evolved replicates from the three strains with the highest proportion of surviving replicates

302 (FH1, P76055, and T101) tended to retain genome sizes similar to the diploid ancestors, while

303 the majority of evolved replicates from other strains varied in genome size (Figure 4). Measured

304 changes in genome size (G1 means) were generally consistent with aneuploidy rather than whole

305 shifts in ploidy (Figure 4, inset panels). 


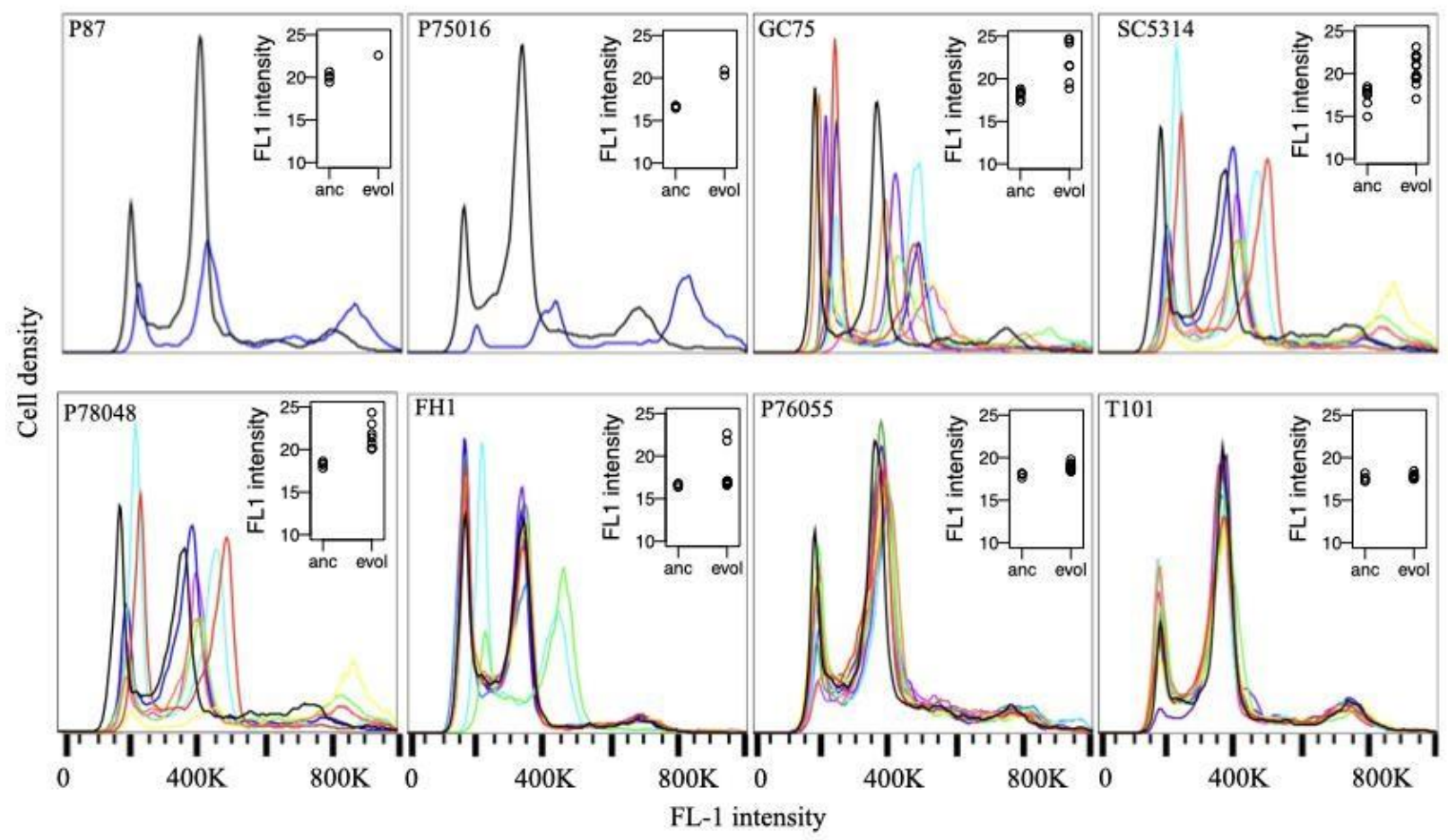

Figure 4. Flow cytometry traces from POS evolved replicates. Each trace is a single evolved replicate, the black trace in each panel is a diploid ancestral replicate. Inset panels display the mean G1 peak from each ancestral (anc) and evolved (evol) replicate for each strain.

Chr6 and ChrR aneuploidy and cross-azole tolerance in evolved replicates

To examine actual karyotypic changes and how they correlate with drug resistance and

tolerance evolution, we performed whole-genome sequencing on 12 evolved replicates from

311 SC5314. All but one evolved replicate had at least one trisomic chromosome. Trisomy of chrR

312 was the most common, with nine replicates having either whole or partial trisomy of this

313 chromosome. Of these nine, two replicates had additional aneuploidies in either chr4 or chr4 and

314 chr6. Two other evolved replicates also had an extra copy of chr6, one alone and one in tandem

315 with an extra copy of chr3 (Figure 5A). We saw no apparent bias towards acquiring an extra

316 copy of the A haplotype or the B haplotype. Most trisomies seem to have swept through the

317 evolved populations, evidenced by a copy number of three from population-level sequencing

318 (Figure 5B). In several cases, the measured copy number was between two and three, likely

319 indicating a polymorphic population, where some cells remained diploid (though we can not rule

320 out that some aneuploidies may be unstable and lost during the grow up from frozen evolved

321 culture for sequencing). A small number of localized copy number variation was also present in

322 evolved lines, and none were suggestive of an adaptive benefit (Table S2). All small CNVs were 
323 either associated with long terminal repeats, major repeat sequences, telomeres, or existed as

324 multiple sites on a single aneuploid chromosome in a single background, suggestive of noisy

325 sequencing.

326 We also subjected these 12 evolved SC5314 replicates to a panel of five additional

327 antifungal drugs to look for cross-resistance and cross-tolerance: voriconazole (VCZ), a triazole

328 like POS and FLC; clotrimazole (CTR) and miconazole (MCZ), which are imidazoles; nystatin

329 (NYT), a polyene; and 5-fluorocytosine (5-FC). Similar to what we found across strain

330 backgrounds for POS and FLC, very few replicates exhibited decreased susceptibility to any

331 additional drugs (Figure 5B). By contrast, nearly all evolved replicates showed increased

332 tolerance to all five azole drugs examined and essentially no change in NYT or 5-FC. There was

333 no clear phenotypic pattern to differentiate evolved strains with ChrR trisomy (or other

334 trisomies) from other replicates, indicating that multiple genotypic pathways seem to provide

335 increased tolerance to POS and that cross-tolerance to other azoles is likely to be a common

336 feature of adaptation to POS. 
bioRxiv preprint doi: https://doi.org/10.1101/2022 01.06.475277; this version posted January 6, 2022. The copyright holder for this preprint (which was not certified by peer review) is the author/funder, who has granted bioRxiv a license to display the preprint in perpetuity. It is made available under aCC-BY-NC-ND 4.0 International license.
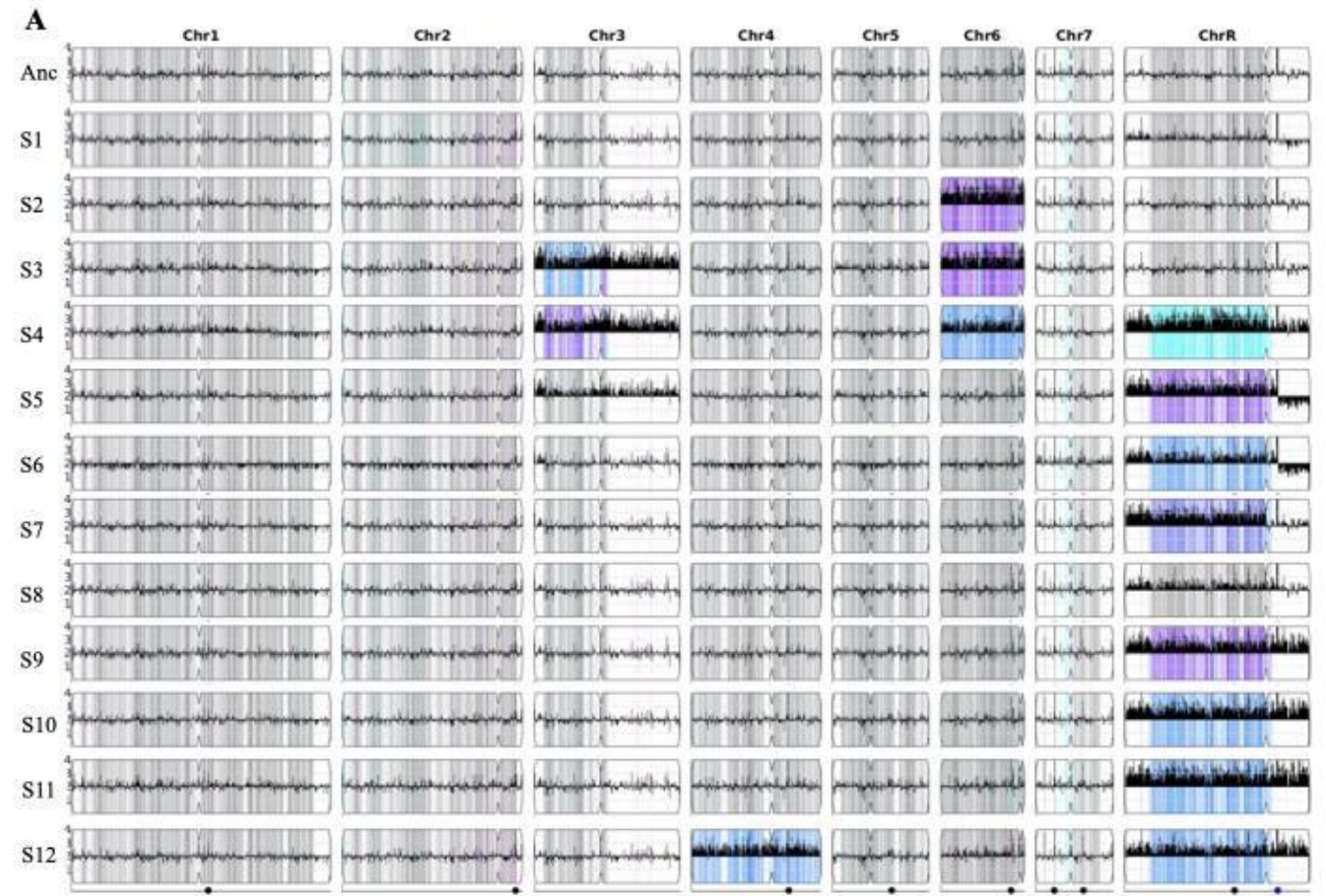

B

C

\begin{tabular}{l|cccccccc}
\multicolumn{1}{c}{} & \multicolumn{1}{c}{ chr1 } & chr2 & chr3 & chr4 & chr5 & chr6 & chr7 & chrR \\
S1 & 2 & 2 & 2 & 2 & 2 & 2 & 2 & 2.2 \\
S2 & 2 & 2 & 2 & 2 & 2 & 3.1 & 2 & 2 \\
S3 & 2 & 2 & 2.9 & 2 & 2.2 & 2.9 & 2 & 2 \\
S4 & 2 & 2 & 2.9 & 1.9 & 1.9 & 2.7 & 1.9 & 3 \\
S5 & 2 & 2 & 2.4 & 2 & 2 & 2 & 2.1 & 2.7 \\
S6 & 1.8 & 1.8 & 2 & 1.8 & 1.8 & 1.8 & 2.1 & 2.5 \\
S7 & 1.9 & 1.9 & 2 & 1.9 & 2 & 2 & 2 & 2.8 \\
S8 & 1.9 & 1.9 & 1.9 & 1.9 & 2 & 1.9 & 2 & 2.4 \\
S9 & 1.9 & 1.9 & 1.9 & 2 & 2 & 2 & 2 & 2.9 \\
S10 & 1.9 & 1.9 & 1.9 & 1.9 & 2 & 2 & 2 & 2.9 \\
S11 & 2 & 2 & 2 & 2 & 2.1 & 2.1 & 2.1 & 3 \\
S12 & 1.9 & 1.9 & 1.9 & 2.6 & 2 & 2.2 & 1.9 & 2.7
\end{tabular}
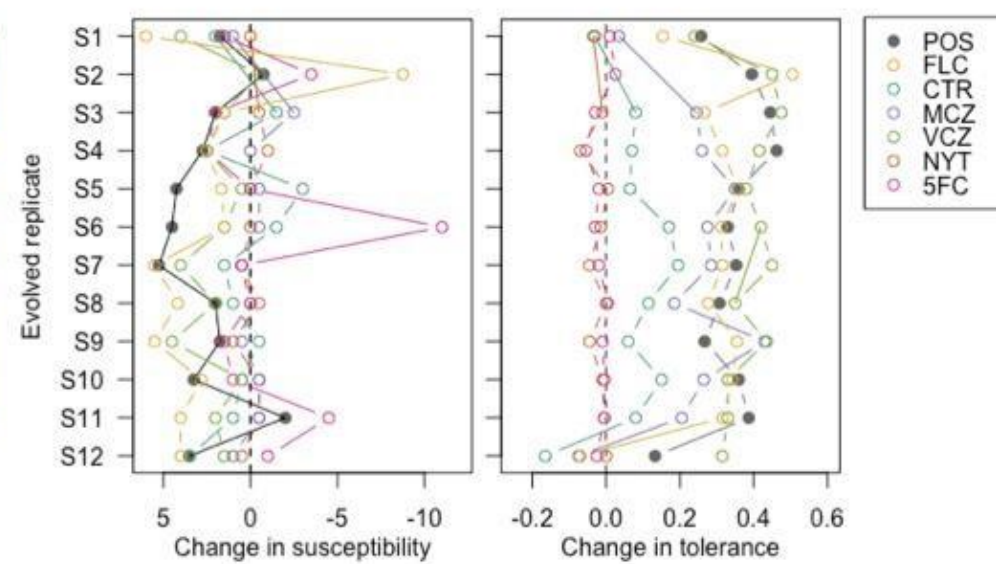

Figure 5. Copy number variation, cross-resistance and cross-tolerance in whole-genome sequenced replicates of SC5314. A) Chromosomal aneuploidy and loss of heterozygosity $(\mathrm{LOH})$ in evolved strains from the Yeast Mapping Analysis Pipeline (YMAP). All strains were compared to the SC5314 reference background. The density of heterozygous SNPs is presented as vertical lines spanning the height of each chromosome cartoon, with the intensity of representing the number of single nucleotide polymorphisms (SNPs) in each $5 \mathrm{~kb}$ bin. SNPs that remain heterozygous are displayed in grey, while those that have become homozygous (i.e LOH regions) are displayed in the color assigned to the homolog that is retained (cyan for the 'A' allele, magenta for the 'B' allele, blue for AAB and purple for ABB). The white regions represent ancestral LOH blocks. CNVs per position are displayed as black histograms drawn vertically from the centerline along the length of the chromosome cartoon. The numbers on the $Y$ axis represent the relative chromosome copy numbers, based upon the whole genome ploidy. The centromere loci are illustrated as an indentation in the scaled chromosome cartoon. The dots represent the positions of the major repeat sequences. B) Median copy number of all reads mapped to each chromosoms. C) The change in susceptibility (left) and tolerance (right) in evolved replicates relative to the SC5314 ancestor. Susceptibility and tolerance were measured from disk assays for posaconazole (POS), fluconazole (FLC), clotrimazole (CLT), miconazole (MCZ), voriconazole (VCZ), nystatin (NYT) and 5-fluorocytosine $(5 \mathrm{FC})$. A negative change in susceptibility is an increase in resistance. 


\section{DISCUSSION}

Experimental laboratory evolution has been an effective method to study pathways of adaptation in a variety of biological contexts (Kawecki et al. 2012; Cooper 2018). Laboratory evolution of microbes at high population sizes (at times termed 'experimental evolution' or 'adaptive laboratory evolution') is a particularly powerful way to examine parallelism and constraint in

344 evolution at genomic and phenotypic levels (Cooper 2018; Gerstein and Sharp 2021). We

345 evolved 12 replicates from eight different strain backgrounds of the opportunistic human fungal 346 pathogen Candida albicans to $0.5 \mathrm{ug} / \mathrm{mL}$ of the drug posaconazole (POS), with transfers every

$34724 \mathrm{~h}$ or $72 \mathrm{~h}$. This level of drug exceeds where we find robust growth in the absence of stress

348 from most ancestral strains, and is an order of magnitude above the defined epidemiological

349 cutoff value of resistance (Arendrup et al. 2011; Procop 2020). As drug tolerance is defined as

350 slow growth in the presence of high levels of drug, we reasoned that a more extended transfer

351 period might select for drug tolerance to evolve. Unfortunately, none of the evolved replicates

352 survived the $24 \mathrm{~h}$ transfers. In the $72 \mathrm{~h}$ transfer experiment, we also found high extinction $(\sim 50 \%$

353 of the replicates), yet the majority of surviving replicates indeed increased in POS tolerance and

354 acquired cross-tolerance to FLC and other azole drugs. Very few studies have (yet) directly

355 examined how different conditions influence how readily tolerance evolves in C. albicans. In an

356 experiment where replicates were evolved with $72 \mathrm{~h}$ transfers to a sub-inhibitory level of

357 fluconazole (i.e., a level of FLC below the MIC), changes in tolerance were also common, but

358 both increases and decreases were observed (Gerstein and Berman 2020). We found a similar

359 result here in YPD when replicates were transferred for 24 h: replicates from one strain

360 background significantly increased in tolerance while replicates from a second significantly

361 decreased. Additional experiments are required to tease apart how different drugs, the level of

362 drug stress (sub-inhibitory vs. inhibitory), and other specifics of environmental exposure drive

363 differences in the propensity to acquire increases in drug tolerance. Nevertheless, it seems clear

364 that there is potential for drug tolerance to evolve quickly, which may have important clinical

365 implications, particularly in cases of persistent candidemia infections when populations are

366 exposed to drug stress for long periods of time, yet the underlying strain remains drugsusceptible

367 (Rosenberg et al. 2018).

368 Evolved POS replicates from the majority, but not all, strain backgrounds increased in 369 their growth ability in the evolutionary level of drug. However, this improvement was primarily 
restricted to the specific drug level strains were evolved in, and the improvement in most replicates was relatively low. Consistent with these results in POS, very few replicates evolved to a subinhibitory level of FLC increased in FLC resistance (Gerstein and Berman 2020), though a second evolution experiment done at the same sub-inhibitory level of FLC found $~ 30 \%$ of replicates had increased resistance (Todd and Selmecki 2020). An evolution experiment that similarly paired a strong selective pressure with a long period of time ( 7 days) between transfers to caspofungin, a different drug class, also found that many evolved diploid lines did not increase in resistance by the end of the 59-day experiment (Avramovska et al. 2021). In contrast, increased FLC MIC was evident in the earliest $C$. albicans evolution experiments conducted in the T101 background in continually increasing levels of FLC for $\sim 330$ generations (Cowen et al. 2000).

Changes in genome size were also widely observed in our POS evolved replicates, similar to previous in vitro evolution experiments in FLC (Selmecki et al. 2006, 2009; Coste et al. 2007; Ford et al. 2015; Gerstein and Berman 2020; Selmecki et al. unpublished) and in strains passaged through a mouse GI model (Ene et al. 2018). Aneuploidies identified in FLCevolved strains typically involve genes known to be involved in FLC resistance mechanisms such as Hsp90, efflux pumps, and multidrug transporters MRR1, CDR1, CDR2, CRZ1 on chr3 (Mount et al. 2018; Todd and Selmecki 2020), and ERG11, TAC1, and calcineurin genes on chr5 (Selmecki et al. 2008). In contrast, in our SC5314 evolved isolates, we predominantly found extra copies of chrR (9 isolates), chr6 (3 isolates), and chr3 (two isolates, in tandem with chr6 aneuploidy in both cases). These aneuploidies were concurrent with increases in tolerance to POS (and other azoles), but not increases in resistance to POS or other tested drugs classes. This is somewhat surprising, as a previous study in a different strain background found that an extra copy of chrR

393 increased resistance to FLC, ketoconazole, and miconazole (Li et al. 2015). Chromosome 3 394 aneuploidy was previously identified to confer an increase in FLC tolerance, due at least in part 395 to an extra copy of the urea transporter NPR2 (Mount et al. 2018). Interestingly, chr6 and chrR 396 were previously found to be the two most common aneuploidies remaining in otherwise euploid 397 strains after 28 days of daily passaging of initially-tetraploids and initiallyaneuploid strains in 398 standard lab YPD (Hickman et al. 2015). This suggests that either these chromosomes carry genes that are beneficial in the context of in vitro evolution in general, or perhaps they simply 
carry the lowest cost in an otherwise euploid background in an environment where aneuploidy frequently occurs.

The rapid evolution of tolerance and cross-tolerance through in vitro evolution has not

403 been previously observed in azoles nor linked to aneuploidy. Todd and Selmecki (2020) did,

404 however, identify three isolates that evolved in an FLC in vitro experiment that had increased

405 copy number of a subset of efflux pump, multidrug transporters, and stress response genes on

$406 \mathrm{chr}$, leading to increased tolerance and resistance to several azoles. Although the mechanism(s)

407 that underlie drug tolerance are still being resolved, there are putative tolerance-associated genes

408 on chrR to target for follow-up studies. Transcriptomics and phenotypic analyses demonstrated

409 that all Rim proteins (including RIM9, on chrR) were important for FLC tolerance (Garnaud et

410 al. 2018). Also intriguing and worthy of further study is GZF3, a GATA-type transcription factor

411 of unknown function, one of two genes (alongside CRZ1) identified in an overexpression screen

412 of 572 genes for fluconazole tolerance (Delarze et al. 2020). Tolerance has both a genetic

413 component, likely involving genes in membrane biosynthesis/integrity and the stress response

414 pathways (Cowen et al. 2014; Rosenberg et al. 2018; Berman and Krysan 2020; Todd and

415 Selmecki 2020), and an environmental component, as growth conditions have been linked to the

416 degree of tolerance exhibited (Gerstein et al. 2016; Berman and Krysan 2020). POS is not a

417 substrate for MDRI or FLU1 encoded efflux pumps (Chau et al. 2004; Hof 2006), hence there

418 are likely to be both pan-azole and azole-specific genetic mechanisms underlying this complex

419 trait.

420 Experimental evolution studies have contributed a wealth of knowledge towards

421 understanding a wide range of factors that influence evolutionary dynamics. We used an in vitro

422 evolution framework at a high level of the second-generation azole drug posaconazole to evolve

423 replicates from diverse $C$. albicans strains. We found that the survival of replicates was strongly

424 dependent on strain background. The majority of evolved replicates improved in rapid growth in

425 the evolutionary level of drug, yet very few replicates increased in POS resistance. Replicates

426 from strains with fewer surviving replicates were more likely to increase in POS drug tolerance

427 and more likely to increase in genome size. Three chromosomal aneuploidies were observed in

428 parallel in multiple evolved lines; these are largely different from those that have been shown to

429 confer an increase in resistance to the related azole drug fluconazole, indicating that the genetic

430 pathway to acquiring posaconazole tolerance is distinct. As the azole drugs are fungistatic rather 
431 than fungicidal, further work is required to determine whether increases in tolerance upon

432 repeated exposure to drugs are common in a clinical setting and whether tolerance is a stepping-

433 stone in the path to resistance or represents a distinct peak in an adaptive trajectory.

\section{DATA AVAILABILITY}

436 Raw data and R scripts used for statistical analyses and to generate figures is available at

437 https://github.com/acgerstein/posaconazole-evolution

\section{ACKNOWLEDGEMENTS}

440 We thank Ola Salama for feedback on troubleshooting experiments and helping shake endless

441 disk assays. We appreciate Dr. Ayush Kumar, Dr. Peter Pelka and Dr. Silvia Cardona for use of

442 plate readers.

\section{FUNDING}

445 ACG was funded by an NSERC Discovery Grant, Start-up funding from the University of

446 Manitoba and a University of Manitoba University Research Grants Program grant. RJK and BS

447 were supported by a University of Manitoba Faculty of Science Undergraduate Research Award,

448 QW and RS were supported by NSERC Undergraduate Student Research Awards. 


\section{REFERENCES}

450

Andrews, S., and Others. 2010. FastQC: a quality control tool for high throughput sequence data. Babraham Bioinformatics, Babraham Institute, Cambridge, United Kingdom.

Abastabar M., T. Hosseini, R. Valadan, M. Lagzian, I. Haghani, et al., 2019 Novel point mutations in cyp51A and cyp51B genes associated with itraconazole and posaconazole resistance in Aspergillus clavatus isolates. Microb. Drug Resist. 25: 652-662. https://doi.org/10.1089/mdr.2018.0300

Abbey D. A., J. Funt, M. N. Lurie-Weinberger, D. A. Thompson, A. Regev, et al., 2014 YMAP: a pipeline for visualization of copy number variation and loss of heterozygosity in eukaryotic pathogens. Genome Med. 6: 100. https://doi.org/10.1186/s13073-014-0100-8

Anderson M. Z., A. Saha, A. Haseeb, and R. J. Bennett, 2017 A chromosome 4 trisomy contributes to increased fluconazole resistance in a clinical isolate of Candida albicans. Microbiology 163: 856-865. https://doi.org/10.1099/mic.0.000478

Arendrup M. C., M. Cuenca-Estrella, J. P. Donnelly, W. Hope, C. Lass-Flörl, et al., 2011 EUCAST technical note on posaconazole. Clin. Microbiol. Infect. 17: E16-7. https://doi.org/10.1111/j.1469-0691.2011.03646.x

Asai K., N. Tsuchimori, K. Okonogi, J. R. Perfect, O. Gotoh, et al., 1999 Formation of azoleresistant Candida albicans by mutation of sterol 14-demethylase P450. Antimicrob. Agents Chemother. 43: 1163-1169. https://doi.org/10.1128/AAC.43.5.1163

Avramovska O., E. Rego, and M. A. Hickman, 2021 Tetraploidy accelerates adaption under drug-selection in a fungal pathogen. bioRxiv 2021.02.28.433243.

Berman J., and D. J. Krysan, 2020 Drug resistance and tolerance in fungi. Nat. Rev. Microbiol. 18: 319-331. https://doi.org/10.1038/s41579-019-0322-2

Bongomin F., S. Gago, R. O. Oladele, and D. W. Denning, 2017 Global and multi-national prevalence of fungal diseases-estimate precision. J Fungi (Basel) 3. https://doi.org/10.3390/jof3040057

Chau A. S., C. A. Mendrick, F. J. Sabatelli, D. Loebenberg, and P. M. McNicholas, 2004 Application of real-time quantitative PCR to molecular analysis of Candida albicans strains exhibiting reduced susceptibility to azoles. Antimicrob. Agents Chemother. 48: 2124-2131. https://doi.org/10.1128/AAC.48.6.2124-2131.2004

Cooper V. S., 2018 Experimental evolution as a high-throughput screen for genetic adaptations. mSphere 3: e00121-18. https://doi.org/10.1128/mSphere.00121-18

Coste A. T., M. Karababa, F. Ischer, J. Bille, and D. Sanglard, 2004 TAC1, transcriptional activator of CDR genes, is a new transcription factor involved in the regulation of Candida albicans ABC transporters CDR1 and CDR2. Eukaryot. Cell 3: 1639-1652. https://doi.org/10.1128/EC.3.6.1639-1652.2004

Coste A., V. Turner, F. Ischer, J. Morschhäuser, A. Forche, et al., 2006 A mutation in Tac1p, a transcription factor regulating $C D R 1$ and $C D R 2$, is coupled with loss of heterozygosity at chromosome 5 to mediate antifungal resistance in Candida albicans. Genetics 172: 21392156. https://doi.org/10.1534/genetics.105.054767

Coste A., A. Selmecki, A. Forche, D. Diogo, M.-E. Bougnoux, et al., 2007 Genotypic evolution of azole resistance mechanisms in sequential Candida albicans isolates. Eukaryot. Cell 6: 1889-1904. https://doi.org/10.1128/EC.00151-07 
Cowen L. E., D. Sanglard, D. Calabrese, C. Sirjusingh, J. B. Anderson, et al., 2000 Evolution of drug resistance in experimental populations of Candida albicans. J. Bacteriol. 182: 15151522. https://doi.org/10.1128/jb.182.6.1515-1522.2000

Cowen L. E., D. Sanglard, S. J. Howard, P. D. Rogers, and D. S. Perlin, 2014 Mechanisms of antifungal drug resistance. Cold Spring Harb. Perspect. Med. 5: a019752. https://doi.org/10.1101/cshperspect.a019752

D’Agostino M., T. Lemmet, C. Dufay, A. Luc, J. P. Frippiat, et al., 2018 Overinduction of CYP51A gene after exposure to azole antifungals provides a first clue to resistance mechanism in Fusarium solani species complex. Microb. Drug Resist. 24: 768-773. https://doi.org/10.1089/mdr.2017.0311

Delarze E., L. Brandt, E. Trachsel, M. Patxot, C. Pralong, et al., 2020 Identification and characterization of mediators of fluconazole tolerance in Candida albicans. Front. Microbiol. 11: 591140. https://doi.org/10.3389/fmicb.2020.591140

Ene I. V., and R. J. Bennett, 2014 The cryptic sexual strategies of human fungal pathogens. Nat. Rev. Microbiol. 12: 239-251. https://doi.org/10.1038/nrmicro3236

Ene I. V., R. A. Farrer, M. P. Hirakawa, K. Agwamba, C. A. Cuomo, et al., 2018 Global analysis of mutations driving microevolution of a heterozygous diploid fungal pathogen. Proc. Natl. Acad. Sci. U. S. A. 115: E8688-E8697. https://doi.org/10.1073/pnas.1806002115

Ene I. V., M. A. Hickman, and A. C. Gerstein, 2021 The interplay between neutral and adaptive processes shapes genetic variation during Candida species evolution. Current Clinical Microbiology Reports 8: 129-138. https://doi.org/10.1007/s40588-021-00171-x

Firinu D., O. Massidda, M. M. Lorrai, L. Serusi, M. Peralta, et al., 2011 Successful treatment of chronic mucocutaneous candidiasis caused by azole-resistant Candida albicans with posaconazole. Clin. Dev. Immunol. 2011: 283239. https://doi.org/10.1155/2011/283239

Flowers S. A., B. Colón, S. G. Whaley, M. A. Schuler, and P. D. Rogers, 2015 Contribution of clinically derived mutations in ERG11 to azole resistance in Candida albicans. Antimicrob. Agents Chemother. 59: 450-460. https://doi.org/10.1128/AAC.03470-14

Fonzi W. A., and M. Y. Irwin, 1993 Isogenic strain construction and gene mapping in Candida albicans. Genetics 134: 717-728.

Ford C. B., J. M. Funt, D. Abbey, L. Issi, C. Guiducci, et al., 2015 The evolution of drug resistance in clinical isolates of Candida albicans. Elife 4: e00662. https://doi.org/10.7554/eLife.00662

Gerstein A. C., and J. Berman, 2015 Shift and adapt: the costs and benefits of karyotype variations. Curr. Opin. Microbiol. 26: 130-136. https://doi.org/10.1016/j.mib.2015.06.010

Gerstein A. C., A. Rosenberg, I. Hecht, and J. Berman, 2016 diskImageR: quantification of resistance and tolerance to antimicrobial drugs using disk diffusion assays. Microbiology 162: 1059-1068. https://doi.org/10.1099/mic.0.000295

Gerstein A. C., and J. Berman, 2020 Candida albicans genetic background influences mean and heterogeneity of drug responses and genome stability during evolution in fluconazole. mSphere 5. https://doi.org/10.1128/mSphere.00480-20

Gerstein A. C., and N. P. Sharp, 2021 The population genetics of ploidy change in unicellular fungi. FEMS Microbiol. Rev. https://doi.org/10.1093/femsre/fuab006

Harrison B. D., J. Hashemi, M. Bibi, R. Pulver, D. Bavli, et al., 2014 A tetraploid intermediate precedes aneuploid formation in yeasts exposed to fluconazole. PLoS Biol. 12: e1001815. https://doi.org/10.1371/journal.pbio.1001815 
Hickman M. A., G. Zeng, A. Forche, M. P. Hirakawa, D. Abbey, et al., 2013 The "obligate diploid" Candida albicans forms mating-competent haploids. Nature 494: 55-59. https://doi.org/10.1038/nature11865

Hickman M. A., C. Paulson, A. Dudley, and J. Berman, 2015 Parasexual ploidy reduction drives population heterogeneity through random and transient aneuploidy in Candida albicans. Genetics 200: 781-794. https://doi.org/10.1534/genetics.115.178020

Hof H., 2006 A new, broad-spectrum azole antifungal: posaconazole--mechanisms of action and resistance, spectrum of activity. Mycoses 49 Suppl 1: 2-6. https://doi.org/10.1111/j.14390507.2006.01295.x

Katragkou A., F. Tsikopoulou, E. Roilides, and T. E. Zaoutis, 2012 Posaconazole: when and how? The clinician's view. Mycoses 55: 110-122. https://doi.org/10.1111/j.14390507.2011.02061.x

Kawecki T. J., R. E. Lenski, D. Ebert, B. Hollis, I. Olivieri, et al., 2012 Experimental evolution. Trends Ecol. Evol. 27: 547-560.

Lamb D. C., D. E. Kelly, T. C. White, and S. L. Kelly, 2000 The R467K Amino acid substitution in Candida albicans Sterol 14 $\alpha$-Demethylase causes drug resistance through reduced affinity. Antimicrob. Agents Chemother. 44: 63-67. https://doi.org/10.1128/AAC.44.1.6367.2000

Lee Y., E. Puumala, N. Robbins, and L. E. Cowen, 2020 Antifungal drug resistance: Molecular mechanisms in Candida albicans and beyond. Chem. Rev. https://doi.org/10.1021/acs.chemrev.0c00199

Levin-Reisman I., I. Ronin, O. Gefen, I. Braniss, N. Shoresh, et al., 2017 Antibiotic tolerance facilitates the evolution of resistance. Science 355: 826-830. https://doi.org/10.1126/science.aaj2191

Levinson T., A. Dahan, A. Novikov, Y. Paran, J. Berman, et al., 2020 Impact of tolerance to fluconazole on treatment response in Candida albicans bloodstream infection. Mycoses. https://doi.org/10.1111/myc.13191

Li X., N. Brown, A. S. Chau, J. L. López-Ribot, M. T. Ruesga, et al., 2004 Changes in susceptibility to posaconazole in clinical isolates of Candida albicans. J. Antimicrob. Chemother. 53: 74-80. https://doi.org/10.1093/jac/dkh027

Li X., F. Yang, D. Li, M. Zhou, X. Wang, et al., 2015 Trisomy of chromosome R confers resistance to triazoles in Candida albicans. Med. Mycol. 53: 302-309. https://doi.org/10.1093/mmy/myv002

Lockhart S. R., C. Pujol, K. J. Daniels, M. G. Miller, A. D. Johnson, et al., 2002 In Candida albicans, white-opaque switchers are homozygous for mating type. Genetics 162: 737-745.

Lockhart S. R., J. P. Frade, K. A. Etienne, M. A. Pfaller, D. J. Diekema, et al., 2011 Azole resistance in Aspergillus fumigatus isolates from the ARTEMIS global surveillance study is primarily due to the TR/L98H mutation in the cyp51A gene. Antimicrob. Agents Chemother. 55: 4465-4468. https://doi.org/10.1128/AAC.00185-11

MacCallum D. M., A. Coste, F. Ischer, M. D. Jacobsen, F. C. Odds, et al., 2010 Genetic dissection of azole resistance mechanisms in Candida albicans and their validation in a mouse model of disseminated infection. Antimicrob. Agents Chemother. 54: 1476-1483. https://doi.org/10.1128/AAC.01645-09

Mount H. O., N. M. Revie, R. T. Todd, K. Anstett, C. Collins, et al., 2018 Global analysis of genetic circuitry and adaptive mechanisms enabling resistance to the azole antifungal drugs. 
PLoS Genet. 14: e1007319. https://doi.org/10.1371/journal.pgen.1007319

Odds F. C., M. E. Bougnoux, D. J. Shaw, J. M. Bain, A. D. Davidson, et al., 2007 Molecular phylogenetics of Candida albicans. Eukaryot. Cell 6: 1041-1052. practice guideline for the management of candidiasis: 2016 update by the Infectious Diseases Society of America. Clin. Infect. Dis. 62: e1-e50. Practice guidelines for the diagnosis and management of Aspergillosis: 2016 Update by the Infectious Diseases Society of America. Clin. Infect. Dis. 63: e1-e60. https://doi.org/10.1093/cid/ciw326

Paul S., I. Kannan, and K. Mohanram, 2019 Extensive ERG11 mutations associated with fluconazole-resistant Candida albicans isolated from HIV-infected patients. Curr Med Mycol 5: 1-6. https://doi.org/10.18502/cmm.5.3.1739

Perepnikhatka V., F. J. Fischer, M. Niimi, R. A. Baker, R. D. Cannon, et al., 1999 Specific chromosome alterations in fluconazole-resistant mutants of Candida albicans. J. Bacteriol. 181: 4041-4049. https://doi.org/10.1128/JB.181.13.4041-4049.1999

Procop G. W., 2020 M59 Epidemiological cutoff values for antifungal susceptibility testing. Clinical and Laboratory Standards Institute.

Rosenberg A., I. V. Ene, M. Bibi, S. Zakin, E. S. Segal, et al., 2018 Antifungal tolerance is a subpopulation effect distinct from resistance and is associated with persistent candidemia. Nat. Commun. 9: 2470. https://doi.org/10.1038/s41467-018-04926-X

Sanglard D., K. Kuchler, F. Ischer, J. L. Pagani, M. Monod, et al., 1995 Mechanisms of resistance to azole antifungal agents in Candida albicans isolates from AIDS patients involve specific multidrug transporters. Antimicrob. Agents Chemother. 39: 2378-2386. https://doi.org/10.1128/aac.39.11.2378

Sanglard D., F. Ischer, M. Monod, and J. Bille, 1997 Cloning of Candida albicans genes conferring resistance to azole antifungal agents: characterization of $C D R 2$, a new multidrug ABC transporter gene. Microbiology 143 ( Pt 2): 405-416. https://doi.org/10.1099/00221287-143-2-405

Sanglard D., and A. T. Coste, 2016 Activity of isavuconazole and other azoles against Candida clinical isolates and yeast model systems with known azole resistance mechanisms. Antimicrob. Agents Chemother. 60: 229-238. https://doi.org/10.1128/AAC.02157-15

Schneider, C.A., Rasband, W.S., and Eliceiri, K.W. 2012. NIH Image to ImageJ: 25 years of image analysis. Nat. Methods 9(7): 671-675.

Selmecki A., A. Forche, and J. Berman, 2006 Aneuploidy and isochromosome formation in drug-resistant Candida albicans. Science 313: 367-370. https://doi.org/10.1126/science.1128242

Selmecki A., M. Gerami-Nejad, C. Paulson, A. Forche, and J. Berman, 2008 An isochromosome confers drug resistance in vivo by amplification of two genes, ERG11 and TAC1. Mol. Microbiol. 68: 624-641. https://doi.org/10.1111/j.1365-2958.2008.06176.x

Selmecki A. M., K. Dulmage, L. E. Cowen, J. B. Anderson, and J. Berman, 2009 Acquisition of aneuploidy provides increased fitness during the evolution of antifungal drug resistance. PLoS Genet. 5: e1000705. https://doi.org/10.1371/journal.pgen.1000705 
Selmecki A. M., Y. E. Maruvka, P. A. Richmond, M. Guillet, N. Shoresh, et al., 2015 Polyploidy can drive rapid adaptation in yeast. Nature 519: 349-352. https://doi.org/10.1038/nature 14187

Sionov E., Y. C. Chang, H. M. Garraffo, M. A. Dolan, M. A. Ghannoum, et al., 2012 Identification of a Cryptococcus neoformans cytochrome P450 lanosterol 14 $\alpha$-demethylase (Erg11) residue critical for differential susceptibility between fluconazole/voriconazole and itraconazole/posaconazole. Antimicrob. Agents Chemother. 56: 1162-1169. https://doi.org/10.1128/AAC.05502-11

Todd R. T., T. D. Wikoff, A. Forche, and A. Selmecki, 2019 Genome plasticity in Candida albicans is driven by long repeat sequences. Elife 8. https://doi.org/10.7554/eLife.45954

Todd R. T., and A. Selmecki, 2020 Expandable and reversible copy number amplification drives rapid adaptation to antifungal drugs. Elife 9. https://doi.org/10.7554/eLife.58349

Wang J. M., R. J. Bennett, and M. Z. Anderson, 2018 The genome of the human pathogen Candida albicans is shaped by mutation and cryptic sexual recombination. MBio 9: e01205-18. https://doi.org/10.1128/mBio.01205-18

Warrilow A. G., A. T. Nishimoto, J. E. Parker, C. L. Price, S. A. Flowers, et al., 2019 The evolution of azole resistance in Candida albicans Sterol 14 $\alpha$-Demethylase (CYP51) through incremental amino acid substitutions. Antimicrob. Agents Chemother. 63. https://doi.org/10.1128/AAC.02586-18

Watson J. V., S. H. Chambers, and P. J. Smith, 1987 A pragmatic approach to the analysis of DNA histograms with a definable G1 peak. Cytometry 8: 1-8. https://doi.org/10.1002/cyto.990080101

Wu W., S. R. Lockhart, C. Pujol, T. Srikantha, and D. R. Soll, 2007 Heterozygosity of genes on the sex chromosome regulates Candida albicans virulence. Mol. Microbiol. 64: 1587-1604. https://doi.org/10.1111/j.1365-2958.2007.05759.x

Xiao L., V. Madison, A. S. Chau, D. Loebenberg, R. E. Palermo, et al., 2004 Three-dimensional models of wild-type and mutated forms of cytochrome P450 14alpha-sterol demethylases from Aspergillus fumigatus and Candida albicans provide insights into posaconazole binding. Antimicrob. Agents Chemother. 48: 568-574. https://doi.org/10.1128/AAC.48.2.568-574.2004

Yang F., F. Teoh, A. S. M. Tan, Y. Cao, N. Pavelka, et al., 2019 Aneuploidy enables crossadaptation to unrelated dDrugs. Mol. Biol. Evol. 36: 1768-1782. https://doi.org/10.1093/molbev/msz104

Yang F., R. T. Todd, A. Selmecki, Y.-Y. Jiang, Y.-B. Cao, et al., 2021a The fitness costs and benefits of trisomy of each Candida albicans chromosome. Genetics 218. https://doi.org/10.1093/genetics/iyab056

Yang F., V. Gritsenko, Y. Slor Futterman, L. Gao, C. Zhen, et al., 2021b Tunicamycin potentiates antifungal drug tolerance via aneuploidy in Candida albicans. MBio 12: e0227221. https://doi.org/10.1128/mBio.02272-21 


\section{SUPPORTING MATERIAL}

Table S1. Two-way ANOVAs comparing drug susceptibility and drug tolerance among ancestral replicates, replicates evolved in YPD with $24 \mathrm{~h}$ transfers and replicates evolved in YPD with $72 \mathrm{~h}$ transfers.

\begin{tabular}{|l|l|l|} 
Strain & Susceptibility ANOVA & Tolerance ANOVA \\
\hline P75016 & $F_{2,32}=0.02, p=0.98$ & $F_{2,32}=0.37, p=0.70$ \\
P87 & $F_{2,32}=21.14, p<0.0001$ & $F_{2,32}=1.61, p=0.22$ \\
GC75 & $F_{2,32}=1.87, p=0.17$ & $F_{2,32}=10.73, p=0.0003$ \\
SC5314 & $F_{2,32}=0.05, p=0.95$ & $F_{2,32}=0.41, p=0.67$ \\
P78048 & $F_{2,32}=1.00, p=0.381$ & $F_{2,32}=0.46, p=0.63$ \\
FH1 & $F_{2,32}=1.74, p=0.19$ & $F_{2,32}=10.97, p=0.0003$ \\
P76055 & $F_{2,32}=12.47, p<0.0001$ & $F_{2,32}=2.34, p=0.11$ \\
T101 & $F_{2,32}=10.82, p=0.0002$ & $F_{2,32}=3.56, p=0.04$ \\
\hline
\end{tabular}

665 
bioRxiv preprint doi: https://doi.org/10.1101/2022.01.06.475277; this version posted January 6, 2022. The copyright holder for this preprint (which was not certified by peer review) is the author/funder, who has granted bioRxiv a license to display the preprint in perpetuity. It is made available under aCC-BY-NC-ND 4.0 International license.
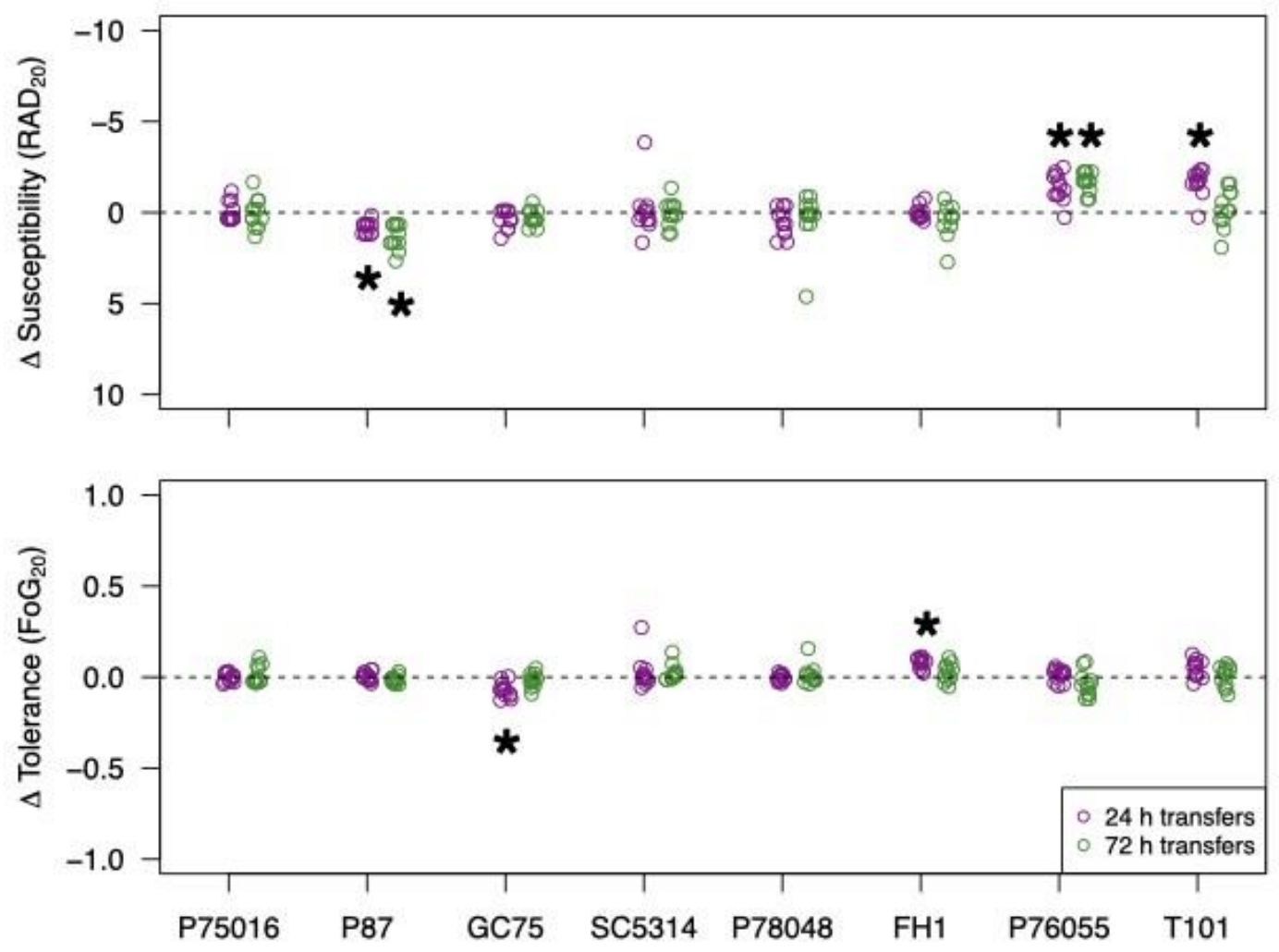

Figure S1. Susceptibility (top) and tolerance (bottom) from YPD-evolved replicates from $24 \mathrm{~h}$ (purple dots) and $72 \mathrm{~h}$ (green dots) transfer experiments assayed on posaconzole disks. Shown is the difference in phenotype between the evolved replicate and the median of 12 ancestral replicates from each. A negative change in susceptibility in the evolved replicate indicates an increase in resistance, and y axis of the top panel is reversed to reflect this. Stars indicate a significance difference compared to the ancestral replicates from a post-hoc Tukey test following a significant ANOA $(\mathrm{p}<0.05)$. 